\title{
MULTISTAGE MEMBRANE DISTILLATION FOR THE TREATMENT OF SHALE GAS FLOWBACK WATER: MULTIOBJECTIVE OPTIMIZATION UNDER UNCERTAINTY
}

Alba Carreño-Parreño ${ }^{a}$, Viviani C. Onishi ${ }^{a}$, Rubén Ruiz-Femenia ${ }^{a, b}$, Raquel Salcedo-Díaz ${ }^{a, b}$, José A. Caballero $^{a, b}$, Juan A. Reyes-Labarta ${ }^{a, b}$

aInstitute of Chemical Process Engineering, University of Alicante, Ap Correos 99, Alicante 03080, Spain

${ }^{b}$ Department of Chemical Engineering, University of Alicante, Ap Correos 99, Alicante 03080, Spain

\section{INTRODUCTION}

Thermal membrane distillation (MD) is an emerging technology to reduce salt concentrations, through hydrophobic semipermeable membranes [1]. MD offers attractive features for flowback water: mobility, modularity, and compactness, contrasting with conventional thermal distillation processes which require a large physical footprint.

In this work, we study the uncertainty associated with flowback water data to obtain a robust design, which is able to deal with a large range of feed compositions and flowrates with a given minimum salt concentration in the outflow brine. A multi-objective stochastic MINLP model is formulated, that seeks to minimize the expected total annual cost (E[TAC]) and simultaneously controlling its variability by minimizing the worst case (WC) risk metric

\section{PROBLEM STATEMENT}

Given are:

The nominal values of the random variables: salt concentration and flowrate of the feed stream

- The outflow brine salinity near to salt saturation conditions to achieve ZLD operation

The superstructure includes several stages with a variable number of membranes. Additionally, for those scenarios where the ZLD specification is not met, a multi-effect evaporation with mechanical vapor recompression (MEE-MVR) can be used after the last stage

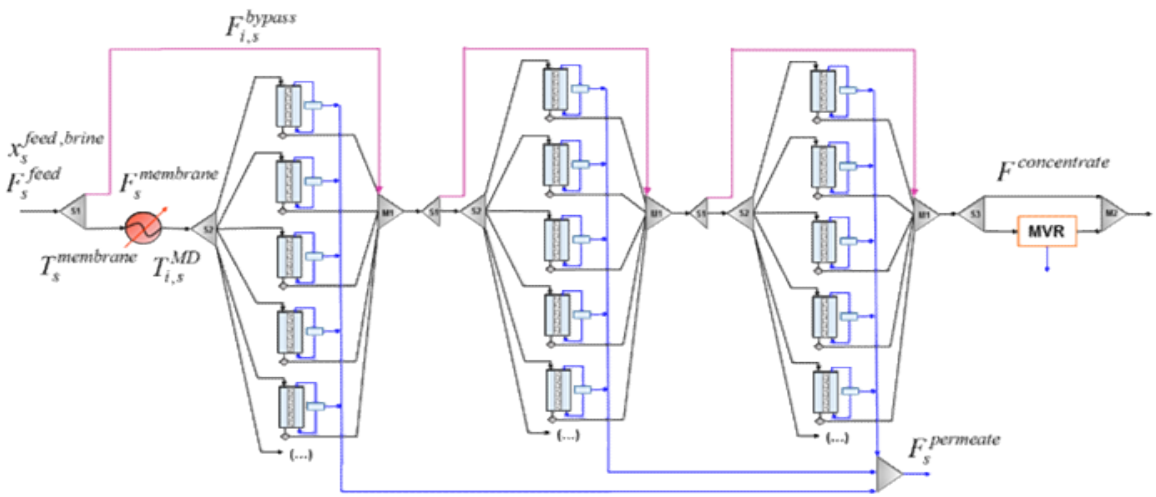

Figure 1 Multistage superstructure for direct contact membrane distillation (DCMD) of flowback water from shale gas production.

- Optimal design of multistage DCMD under uncertainty.

- Mathematically formulated as a bi-criterion stochastic MINLP for the minimization of expected TAC and its variability, which was controlled by WC metric.

- The solutions obtained are intended to guide the decision-maker towards the adoption of more sustainable DCMD designs.

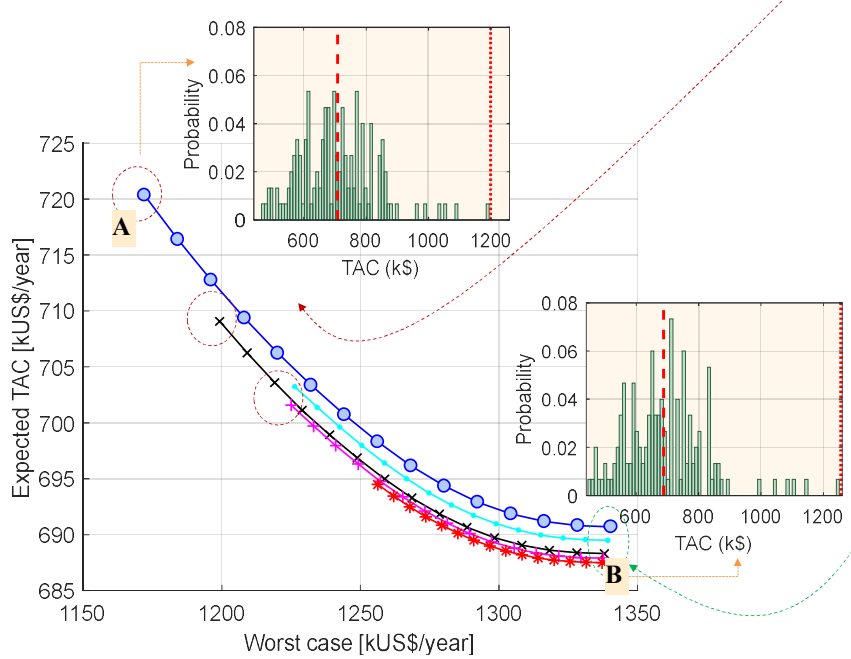

Figure 4 Pareto set of solutions for the economic performance (E[TAC]) and financia risk metric (WC) at different flowsheet configurations, and probability distributions of the TAC associated with the minimum E[TAC] and WC extreme solutions

\section{METHODOLOGY}

The uncertainty is represented by 100 correlated scenarios generated using Monte Carlo sampling on marginal normal distributions that characterize the random variables salinity and mass flowrate (Figure 2)

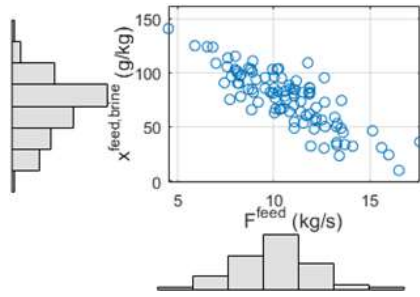

Figure 2 Correlated distribution ( $\rho=-0.8$ ) using marginal normal probability distribution for the uncertain parameters.

A decomposition strategy based on the sample average approximation algorithm [2] is used (Figure 3)

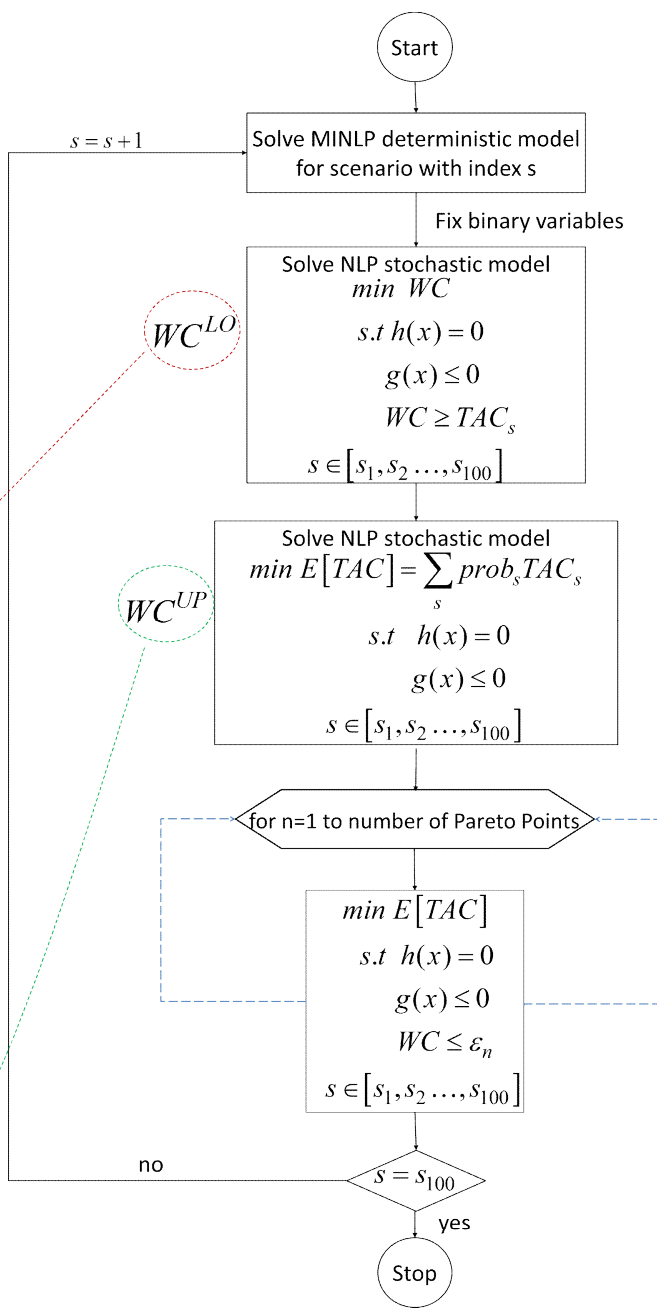

Figure 3. Modified sample average approximation (SAA) algorithm

\section{ACKNOWLEDGEMENTS} agreement No. 640979 .

\section{REFERENCES}

[1] Elsayed, N.A., Barrufet, M.A., Eljack, F.T., El-halwagi, M.M., 2015. Optimal Design of Thermal Membrane Distillation Systems for the Treatment of Shale Gas Flowback Water, Desalination

[2] Kostin, A.M., Guillén-Gosálbez, G., Mele, F.D., Bagajewicz, M.J., Jiménez, L., 2012. Design and planning of infrastructures for bioethanol and sugar production under demand uncertainty. Chem. Eng. Res. Des. 